\title{
Ciguatera fish poisoning in an international ship crew in Saint John Canada: 2015
}

\author{
Muecke $\mathrm{C}^{1^{*}}$, Hamper $\mathrm{L}^{2}$, Skinner $\mathrm{AL}^{3}$, Osborne $\mathrm{C}^{2}$. \\ ${ }^{1}$ Office of the Chief Medical Officer of Health, Department of Health, Fredericton, NB \\ ${ }^{2}$ South Region Health Protection Branch, Office of the Chief Medical Officer of Health, Fredericton, NB \\ ${ }^{3}$ Travelling Public Program (Eastern Region), Office of Border and Travel Health, Centre for Emergency Preparedness \\ and Response, Public Health Agency of Canada, Moncton, NB
}

*Correspondence: cristin.muecke@gnb.ca

\begin{abstract}
An international ship crew presented for medical care in Saint John, New Brunswick, following rapid onset of gastrointestinal and in some cases neurological and cardiac symptoms after a common fish meal. Ciguatera poisoning was identified as the cause of illness. This report describes the public health investigation and management of this incident, including collaboration between the implicated provincial and federal authorities.
\end{abstract}

\section{Case presentation}

On April 11, 2015, nine male crew members of an international cargo vessel docked in Saint John, New Brunswick (NB) presented to the emergency department at the Saint John Regional Hospital (SJRH) with gastrointestinal symptoms (nausea, vomiting, diarrhea and abdominal cramps). Other significant symptoms included dizziness, weakness and peripheral extremity paresthesia. When examined, several of the men were further found to have hypotension and bradycardia. All were admitted for intensive care-level monitoring and management, including continuous cardiac monitoring, atropine for bradycardia, antiemetics and intravenous rehydration. Within a few hours, five more crew members presented with the same symptoms and were also admitted.

The crew members reported that they had consumed a common meal of fish stew using fish they had caught during their voyage in the Caribbean and had begun feeling ill 1-1.5 hours afterwards. The attending physicians consulted with the regional poison centre in Halifax and identified ciguatera fish poisoning as the most likely diagnosis. The incident was reported to the public health department.

\section{Involved agencies}

This situation required a response from both federal and provincial public health services as well as the local regional health authority $(\mathrm{RHA})$. Clarity regarding the respective roles of each agency was key to ensuring that timely public health actions were implemented and that organizational mandates were respected.

The Travelling Public Program (TPP) of the Public Health Agency of Canada (PHAC) responded to this enteric disease outbreak as part of their mandate to ensure sanitation standards on public conveyances (in this case, an international conveyance in Canadian waters) (1). The TPP is also responsible for administering the Ship Sanitation Certificate Program (as per the World Health Organization's International Health Regulations). The PHAC Quarantine Program was not activated as it was determined that the crew had not contracted a communicable illness as defined in the federal Quarantine Act. 
The Health Protection Branch of the Office of the Chief Medical Officer of Health (NB Department of Health) also became involved because a notifiable event had been reported by clinical staff at the $\mathrm{SJRH}$, as is required under the NB Public Health Act (2) and associated regulations (3).

The Emergency Preparedness and Response Branch (NB Department of Health) provided coordination support between impacted provincial health system agencies. Clinical and emergency incident management support was provided by Ambulance New Brunswick and various staff of the SJRH, Horizon Health Network. Laboratory support was provided by the Canadian Food Inspection Agency (CFIA) food chemistry laboratory in Dartmouth, Nova Scotia.

\section{Investigation and methods}

NB clinicians are required to report clusters of illness thought to be food- or water-borne verbally within one hour to their regional public health office. They are also required to report unusual illness (not expected to occur in NB or unknown etiology) within 24 hours. The on-call public health staff (public health inspector and the medical officer of health) liaised with the SJRH staff to collect initial information on the clinical status and probable diagnosis of the affected crew. Control measures included closure of the ship's galley kitchen, monitoring of remaining crew members, obtaining regular clinical updates on hospitalized crew members and liaising with federal counterparts regarding the inspection of the galley kitchen and remaining food.

TPP Environmental Health Officers were dispatched on April 12, 2015 to conduct an inspection of the ship's food preparation and storage area, provide food safety advice, collect food samples and dispose of any potentially contaminated food products. Samples of fish left over from the suspect meal and samples of frozen fish that were also caught in the Caribbean were sent to the CFIA laboratory (Dartmouth) for species analysis and toxin testing.

Initial interviews of the discharged affected crew using a standardized enteric illness questionnaire were conducted on April 14, 2015. A letter to crew members, outlining the cause and prevention of ciguatera fish poisoning as well as prognosis and post-illness advice was also distributed to the crew on April 14, 2015. A final interview of the affected crew members was conducted jointly by federal and provincial investigative staff on April 17, 2015. Medical records for all hospitalized crew members were obtained from Horizon Health Network and reviewed for further information on clinical presentation and course in hospital.

\section{Results}

There were 19 crew members onboard the cargo vessel when the outbreak occurred, of which fourteen (73.7\%) had eaten the suspect meal of fish soup. The five remaining crew were either sleeping or ate the alternative pork meal that was served. All crew that ate the fish meal were ill and required admission to hospital for intensive care-level monitoring and management. A Code Orange (mass casualty event) was initiated by the SJRH to manage this large influx of critically ill patients.

The galley kitchen was closed until a full inspection was conducted and the remaining crew obtained food off-ship during that time. Remaining crew members were monitored for approximately 12 hours until it could be firmly established that there were no remaining individuals who were susceptible.

The average length of hospital stay for those affected was 3.5 days and one individual required a readmission for continued symptoms. Following discharge, the crew members were repatriated by the ship owners as several of them were considered to be "unfit for duty" by attending physicians.

The severity of symptoms directly correlated with the amount of fish soup that was consumed and what part of the fish was ingested. For example, the individual who experienced the most severe symptoms ate the largest portion of the meal including the head of the fish.

Further questioning revealed that the crew had line fished off the boat while anchored in the Bahamas and had caught more than 125 kilos of fish in this manner. The fish was separated and frozen intact for crew 
consumption and portions were eaten daily during their voyage north to Saint John, NB. While at the port in Saint John one of the larger fish was thawed then prepared by removing entrails, gills, and fins, descaled, and then cooked in a fish soup with the head still attached.

The fish stew specimen was reported as 'suspected positive' for ciguatoxin (due to lack of analytical standards the lab was unable to quantify the concentration of ciguatoxin in the sample). The remaining fish on the ship that was unlabelled or obtained from an unapproved food supplier was soaked in a strong sodium hypochlorite solution to render it inconsumable and then disposed.

\section{Discussion}

Ciguatera is a foodborne illness that is caused by eating reef fish contaminated with a toxin called "ciguatoxin". Ciguatoxin is colorless, odorless and tasteless and the fish are not altered in appearance. The toxin cannot be destroyed by cooking, smoking, freezing, canning, salting or drying. This poison is produced by dinoflagellates, small organisms that attach to algae growing in warm ocean reef areas. Small plant eating fish ingest these toxic algae and are then eaten by larger predatory fish, which are in turn consumed by humans (4). Fish in affected areas are not uniformly impacted, so it is possible for only a few fish out of any given catch to contain sufficient levels of toxin to cause illness. The toxin is lipid-soluble and concentrates in the head, viscera and roe of the fish (5). The public health system played an important role in conveying this information to the crew (and by extension to their superiors) in order to better understand the cause of the situation and how to prevent it in the future, thus providing an important complement to clinical discharge advice.

Symptoms of ciguatera fish poisoning can occur within minutes, but generally develop within 24 hours of eating contaminated fish. Initial gastrointestinal symptoms include nausea, vomiting, diarrhea and abdominal pain. These symptoms may last several days. Neurological symptoms develop after the initial gastrointestinal symptoms, and include tingling and numbness around the mouth, lips, throat, arms and legs, sore muscles and tooth pain, temperature reversal (hot things feel cold and cold things feel hot), feeling tired, headaches and itchy skin. In severe cases, neurological symptoms can last months or longer and may be worsened by changes in dietary behavior (such as dieting or high protein meals), alcohol consumption, exercise or sexual intercourse (5). Initial clinical information and ongoing monitoring of the hospitalizations were an important aspect of the public health assessment, however there were key discrepancies noted in the information received (such as a lack of reporting of neurological symptoms and absence of routine stool testing) that prompted subsequent medical chart review. While acknowledging the challenge of multiple clinician involvement, clear communication of public health needs, via direct public health physician to clinical physician contact would help to ensure that public health considerations are integrated with clinical management.

Diagnosis is based on astute recognition of the clinical presentation and compatible food exposure history. No human diagnostic testing is currently available. However, stool specimens should be routinely collected to rule out other more common causes of foodborne intoxications. If food specimens are available they can be collected and tested for presence of ciguatera toxin. There is no antidote for ciguatera poisoning, and people who have consumed ciguatoxin receive symptomatic treatment (6). Most people suffering from ciguatera fish poisoning will recover completely within a few days or weeks, but in very rare cases, ciguatera can be fatal (4).

This outbreak investigation presented an important learning opportunity regarding inter-agency dynamics and communication. Perhaps the most significant issue was early overlap regarding the relative roles of the federal and provincial agencies in the assessment and initial response to this situation. This was due in part to the fact that the federal and provincial agencies were notified through two separate processes - in the case of the TPP, by notification from Quarantine Services (who liaise with port authorities) and in the case of the Health Protection Branch office, by the hospital receiving the patients. This caused some initial duplication, but when we reviewed this afterwards, we decided not to change any processes as we concluded that it was better to have some redundancies in the system rather than a potential gap. We also concluded that the maintenance of ongoing relationships and links between agencies is critical to ensure that 
roles and responsibilities are clear during a response. When incidents occur out of regular business hours, direct communication is particularly helpful to those who may be cross-covering other responsibility areas.

Recent research has suggested that climate change could increase the burden of ciguatera fish poisoning by expanding the range of suitable warm water habitats (7). However, it is also possible that if sea surface temperatures get too high, ciguatera toxin production by dinoflagellates could decrease. (8) In the meantime, prevention relies on public and industry awareness of ciguatera-affected areas and fish species (in particular, requiring that food for international shipping crews be obtained only from approved sources), since ciguatera toxic fish are not easily detected and no known preparation method can remove or destroy the toxin.

\section{Acknowledgements}

We wish to thank the following individuals for their invaluable assistance in this incident: Denis Belliveau (Travelling Public Program, Office of Border Travel Health, Moncton); Tamela Carroll (Office of the Chief Medical Officer of Health, Fredericton); Sharf Chowdhury (Emergency Management, Horizon Health Network); Jessica Crawley (South Region Health Protection Branch, Saint John, NB); Carolin Galvin (Emergency Preparedness and Response Branch, NB Department of Health); Steven Kempton (Emergency Preparedness and Response, Public Health Agency of Canada); Bruce Macfarlane (Communications, NB Department of Health); Jeff van de Riet (Food Safety Science Directorate, Canadian Food Inspection Agency).

\section{References}

(1) Public Health Agency of Canada. Office of Border Health Services [Internet]. Ottawa: Public Health Agency of Canada; 2015. Available from: http://www.phac-aspc.gc.ca/cepr-cmiu/ophs-bssp/quar-eng.php.

(2) Public Health Act of New Brunswick. S.N.B. 1998, c. P-22.4. [Internet]. http://laws.gnb.ca/en/browsetitle?letter=P.

(3) New Brunswick Regulation 2009-136 under the Public Health Act. (OC 2099-455) [Internet]. http://laws.gnb.ca/en/browsetitle?listregulations=P-22.4\&letter=P\#P-22.4.

(4) Government of Canada. Ciguatera [Internet]. Ottawa: Government of Canada; 2015. http://travel.gc.ca/travelling/health-safety/diseases/ciguatera.

(5) Centers for Disease Control and Prevention (CDC). Ciguatera fish poisoning - Texas, 1997. MMWR Morb Mortal Wkly Rep. 1998 Aug;47(33):692-4. http://www.cdc.gov/mmwr/preview/mmwrhtml/00054548.htm

(6) Schlaich C, Hagelstein JG, Burchard GD, Schmiedel S. Outbreak of ciguatera fish poisoning on a cargo ship in the Port of Hamburg. J Travel Med. 2012;19(4): 238-42.

(7) Gingold DB, Strickland MJ, Hess JJ. Ciguatera fish poisoning and climate change: Analysis of National Poison Center data in the United States, 2001-2011. Environ Health Perspect. 2014;122(6):580-6.

(8) Llewellyn LE. Revisiting the association between sea surface temperature and the epidemiology of fish poisoning in the South Pacific: Reassessing the link between ciguatera and climate change. Toxicon. 2010;56(5):691-7. 